\title{
$\mathrm{Sr}_{2} \mathrm{Ru}_{1-\mathrm{x}} \mathrm{Cu}_{\mathrm{x}} \mathrm{O}_{4 . \mathrm{y}}(\mathbf{0 . 0} \mathbf{0} \mathrm{x} \leq 0.5)$ 화합물의 구조 및 전달 특성에 대한 연구
}

\author{
박 중 첨* \\ 신라대학교 나노소재 공학과 \\ (2003, 9, 26 접수)
}

\section{Study on the Structural and Transporting Property of $\mathrm{Sr}_{2} \mathrm{Ru}_{1-x} \mathrm{Cu}_{x} \mathrm{O}_{4-y}(0.0 \leq x \leq 0.5)$}

\author{
Jung-Chul Park* \\ Department of Nano Material Science and Engineering, Nano Applied Technology Research Center, \\ Silla University, Busan 617-736, Korea \\ (Received September 26, 2003)
}

요 약. 고상반응으로 $\mathrm{Sr}_{2} \mathrm{Ru}_{1-\mathrm{x}} \mathrm{Cu}_{\mathrm{x}} \mathrm{O}_{4 \mathrm{y}}(0.0 \leq \mathrm{x} \leq 0.5)$ 화합물을 합성하였다. $\mathrm{X}$ 선 회절 분석 결과에 대한 Rietveld 정 밀화로부터 합성된 $\mathrm{Sr}_{2} \mathrm{Ru}_{1-x} \mathrm{Cu}_{x} \mathrm{O}_{4-4}$ 화합물은 $0 \leq \mathrm{x} \leq 0.3$ 의 $\mathrm{Cu}$ 치환 범위에서는 모두 단일상의 정방정졔 구조를 갖는 $\mathrm{K}_{2} \mathrm{NiF}_{4}$ 형태의 구조룰 취하지만, $0.4 \leq \mathrm{x} \leq 0.5$ 의 범위에서는 미량의 $\mathrm{Sr}_{2} \mathrm{CuO}_{3}$ 화합물의 회절 피이크가 관찰되는 이중상 을 갖는 화합물로 존재한다는 사실을 할 수 있었다. $\mathrm{Sr}_{2} \mathrm{RuO}_{4}$ 화합물의 $\mathrm{Ru}$ 자러에 $\mathrm{Cu}$ 이온을 부분적으로 치환할 때의 전이금속 이은인, $\mathrm{Ru}$ 와 $\mathrm{Cu}$ 이온의 원자가 상태는 $\mathrm{X}$ 선 전자 분광법으로 확인하였다. $\mathrm{Ru} 3 \mathrm{p}_{3 / 2}$ 전자와 $\mathrm{Cu} 2 \mathrm{p}_{3 n}$ 전자의 결합에너저 측정으로부터 $\mathrm{Ru}^{4+}, \mathrm{Cu}^{2+}$ 를 갖는 것으로 확인되었다. $\mathrm{Sr}_{2} \mathrm{RuO}_{4}$ 화합물의 $\mathrm{Ru}$ 자리에 치환하는 $\mathrm{Cu}$ 이온의 농도를 중가할수록 $\mathrm{Ru}-\mathrm{O} 1(\times 4)$ 와 $\mathrm{Ru}-\mathrm{O}_{2}(\times 2)$ 의 결합길이 차이가 $\Delta=0.1329 \AA\left(\mathrm{Sr}_{2} \mathrm{RuO}_{4}\right.$ 경우)에서 $\Delta=0.0383 \AA$ $\left(\mathrm{Sr}_{2} \mathrm{Ru}_{0,7} \mathrm{Cu}_{0.3} \mathrm{O}_{4 . y}\right.$ 경우)으로 변하며, c/a 역시 감소하는 경항을 나타내고 있다. 따라서, $\mathrm{Sr}_{2} \mathrm{RuO}_{4}$ 화합물의 $\mathrm{Ru}$ 자리에 $\mathrm{Cu}$ 이온을 치환함에 따라 $\mathrm{RuO}_{6}$ 팔면체의 국부 대칭성의 변화에 의해 결정구조가 정방정졔로의 변화를 수반하면서, 이에 따른 $\mathrm{Sr}_{2} \mathrm{Ru}_{1-x} \mathrm{Cu}_{\mathrm{x}} \mathrm{O}_{4 y}$ 의 전달톡성이 금속에서 반도체로 변화한다.

추제어: $\mathrm{Sr}_{2} \mathrm{Ru}_{1 \cdot x} \mathrm{Cu}_{x} \mathrm{O}_{4,}$, 국부대칭성의 변화, 전달톡성

ABSTRACT. $\mathrm{Sr}_{2} \mathrm{Ru}_{1, x} \mathrm{Cu}_{\mathrm{x}} \mathrm{O}_{4 y}(0.0 \leq \mathrm{x} \leq 0.5)$ compounds were prepared using a conventional solid state reaction. Based on the Rietveld refinements of $\mathrm{X}$-ray diffraction results, it is revealed that $\mathrm{Sr}_{2} \mathrm{Ru}_{1-x} \mathrm{Cu}_{x} \mathrm{O}_{4-y}$ compounds are the single phases with $\mathrm{K}_{2} \mathrm{NiF}_{4}$ type tetragonal system in the range of $0=\mathrm{x}=0.3$, while the mixed phases of $\mathrm{Sr}_{2} \mathrm{RuO}_{4}$ and $\mathrm{Sr}_{2} \mathrm{CuO}_{3}$ in the range of $0.4 \leq x \leq 0.5$. By means of $X$-ray photoelectron spectroscopy, the valence states of $\mathrm{Ru}$ and $\mathrm{Cu}$ in $\mathrm{Sr}_{2} \mathrm{Ru}_{1-x} \mathrm{Cu}_{x} \mathrm{O}_{4 y}$, have been confirmed to $4+$ and $2+$, respectively. The bond length difference between $\mathrm{Ru}-\mathrm{O}_{1}(\times 4)$ and $\mathrm{Ru}-\mathrm{O}_{2}(\times 2)$ in $\mathrm{RuO}_{6}$ octahedron is gradually decreased with increasing $\mathrm{Cu}$ content in $\mathrm{Sr}_{2} \mathrm{Ru}_{1 \cdot x} \mathrm{Cu}_{x} \mathrm{O}_{4 \cdot y}$, which results in the lower c/a ratio. So, it might be assured that the variation of local symmetry of $\mathrm{RuO}_{6}$ octahedron is very closely retated to the transporting property of $\mathrm{Sr}_{2} \mathrm{Ru}_{1-x} \mathrm{Cu}_{x} \mathrm{O}_{4 . y}$ compounds. The behavior of resistivity discloses that the metallic property in $\mathrm{Sr}_{2} \mathrm{RuO}_{4}$ changes into the semiconducting one in proportion to the $\mathrm{Cu}$ content in $\mathrm{Sr}_{2} \mathrm{Ru}_{1-x} \mathrm{Cu}_{2} \mathrm{O}_{4 y}$.

Keywords: $\mathrm{Sr}_{2} \mathrm{Ru}_{1 \cdot x} \mathrm{Cu}_{x} \mathrm{O}_{4 y}$, The Variation of Local Symmetry, The Transporting Property 


\section{서}

$\mathrm{Sr}_{2} \mathrm{RuO}_{4}$ 화합물은 $\mathrm{La}_{2} \mathrm{CuO}_{4}$ 화합물과 유사한 $\mathrm{K}_{2} \mathrm{NiF}_{4}$ 형태의 구조롤 가저는 화합불이다.

$\mathrm{Sr}+0 \mathrm{~L} \mathrm{La}$ 자리에 부분적으로 치환된 $\mathrm{La}_{2 \times x} \mathrm{Sr}_{x} \mathrm{CuO}_{4}$ 화 합물은 대략 $40 \mathrm{~K}$ 이하에서 초전도성을 나타내는 반면 에 $\mathrm{S}_{5} \mathrm{RuO}_{4}$ 화합물은 대략 $1 \mathrm{~K}$ 이하에서 초전도성이 나타난다. 1.2 따라서 $\mathrm{Sr}_{2} \mathrm{RuO}_{4}$ 화합문은. 촌전도성여 나타 나는 온노는 매우 낮지만 구리화합눌과 동일한 결점구 조를 갖기 때문에 초전도상태와 정상상태의 특성을 연 구하기에 적합한 화합꿀로 간즈도고 있다. $100 \mathrm{mK}$ 과 $973 \mathrm{~K}$ 사이의 온도영역에서 $\mathrm{Sr}_{2} \mathrm{RuO}$ 의 결정구조에 대 한 연구들이 몇몇 연구그룹늘에 의해 수행되었다. ${ }^{2 k}$ 중 성자 회절 연구에서, Vogt와 Buttrey는 팔면체의 축방 향의 $\mathrm{Ru}-\mathrm{O}_{2}$ 결합길이가 $100 \mathrm{~K}$ 와 $150 \mathrm{~K}$ 에서 비정상젹 인 것으로 관찰되었다. 이러한 관찰이 사실이라면, 이 것은 귺속-비금속의 상전이와 일치하며 구조적인 특성 과 전자적 특성 사이에 밀접한 상호연관성이 있다는 것 을 시사하고 있는 것이나.

초선도성을 갖는 $\mathrm{La}_{2} \mathrm{CuO}_{4}$ 유사 화합물들의 구조는 다른 금속산화물 형태의 초전도체들보다 휠쌘 간단하 기 때문에 초전도성의 연주를 위한 화합물로쌩 $\mathrm{La}_{2} \mathrm{CuO}_{4}$ 유사 화합물늘이 널리 이용되고 있는 실정이다. $\mathrm{La}$ 원 소가 존재하지 않는 $\mathrm{Sr}_{2} \mathrm{CuO}_{3}$ 화합물은 정방정계 $\mathrm{K}_{2} \mathrm{NiF}_{4}$ 구조를 갖는 (혹은 $\mathrm{Nd}_{2} \mathrm{CuO}_{4}$ 구조) $\mathrm{Cu}$ 와 $\mathrm{O}$ 원소로 구성 된 퐐면체 배위구조에서 석도자러(equatorial site)의 산 소가 규칙젹으로 $1 / 2$ 만큼 결핍되어 사각형 배위구조를 갖는 $\mathrm{CuO}_{4}$ 단위들이 사슬처럼 현결되어 있으며 이때 $\mathrm{Cu}$ 의 원자가는 +2 를 갖는다. ${ }^{7.8}$

$\mathrm{LaSrCuO}_{4}$ 갇은 화합물에서 $\mathrm{Cu}(\mathrm{III})$ 롤 안정화 시키기 위해 산소고악방법을 사용하는 것처럼, $\mathrm{Sr}_{2} \mathrm{CuO}_{3}$ 화합 물의 산소코압으로 처리하여 산소이온을 격자내로 유 입시켜 $70 \mathrm{~K}$ 이하에서 초전도성이 나타나는 $\mathrm{Sr}_{2} \mathrm{CuO}_{4+5}$ $(\delta \simeq 0.9)$ 화합불을 합성하고 있다. ${ }^{911}$

$\mathrm{Sr}_{2} \mathrm{RuO}_{4}$ 화합물과 $\mathrm{Sr}_{2} \mathrm{CuO}_{3}$ 화합물이 동일한 정밤결 성계의 $\mathrm{K}_{2} \mathrm{NiF}_{4}$ 형 구조롤 취한다는 결정구조학적 동일 성과 $\mathrm{Sr}_{2} \mathrm{RuO}_{4}$ 의 전자구조는 $\mathrm{Ru} 4 \mathrm{~d}$ 와 $\mathrm{O} 2 \mathrm{p}$ 전자둔의 혼성에 의해 결정되며 $\mathrm{Sr}_{2} \mathrm{CuO}_{3}$ 의 전자구조 역시 $\mathrm{Cu} 3 \mathrm{~d}$ 와 $\mathrm{O} 2 \mathrm{p}$ 전자들에 의해 결성됙다는 전자구조 형성의 유사성이 두 화합물에서 나타넌다. 또한, 전이금속 원 손들인 $\mathrm{Cu}$ 와 $\mathrm{Ru}$ 의 이온반경을 ${ }^{12}$ 살펴보변 $\mathrm{Cu}^{+1}(0.73 \AA)$, $\mathrm{Ru}^{4+}(0.62 \hat{\mathrm{A}})$ 으로 유사한 이은반경을 가지고 있음을 알
누있다.

따라서, 본 연구에서는 $\mathrm{Sr}_{2} \mathrm{RuO}_{3}$ 와 $\mathrm{Sr}_{2} \mathrm{CuO}_{3}$ 화합물과 의 고횽체 영역을 결정하여 $\mathrm{Sr}_{2} \mathrm{Ru}_{\mathrm{l}-\mathrm{x}} \mathrm{Cu}_{\mathrm{x}} \mathrm{O}_{4}(\mathrm{x}=0.0,0.1$, $0.2,0.3,0.4,0.5)$ 화합물을 합성하여 이늘 화합물의 결 점구조학적 변화 및 전자구조의 변화에 따른 전달특성 의 변화를 고찰하였다.

\section{심 험}

시료합섬. 전형적인 고체반응법을 사용하여 시료를 합성하였다.

$\mathrm{SrCO}_{3}$ (Aldrich, $99.995 \%$ ), $\mathrm{RuO}_{2}$ (Aldrich, $99.9 \%$ )와 $\mathrm{CuO}$ (Aldrich, $99.99 \%$ )를 합성하고자 하는 시료의 몰비 로 칭랑한 후 잘 갈아준 더음 $900{ }^{\circ} \mathrm{C}$ 로 유지한 전기로 에서 18지간 동안 열처리하였다. 위의 시로를 모르타르 에서 잘 찰하서 펠렛 성형기로. 펜뎃을 만든어서 $1200{ }^{\circ} \mathrm{C}$ 에서 18 시간동안 열처러하여 시로늘을 합성하였다.

분석방법 및 측점기기. 합성된 시료의 결정성과 단일 상으로의 합성여부를 확인하기 위하여 powder X선 회 전분석법을 채택하였으며, 구조에 대한 상세한 정보를 얻기 워한 화절도는 $40 \mathrm{KV}, 300 \mathrm{~mA}$ 의 X-선 광원을 갖는 회절기에 장착된 회전 타켓을 이용하였으며 $\mathrm{Cu} \mathrm{K \alpha}$ 북 사선은- graphite 단색화 장치를 사용하였다. step 넓이 가 $0.02^{\prime \prime}, 1$ 초의 step 시간에서 $20=20-100$ 의 범위에서 자료를 수집하였다. 회절 위치와 새기에 대한 상새한 정보는 Rielveld 분석용 RIETAN ${ }^{1}$ 프로.그램을 사용하 였으며, 전기저항은 직류 4단자 법으로 측정하였다. 시 로의 온도는 밀폐순환형 $\mathrm{He}$ 냄농기(APD HC-2) 를 이 용하여 $10 \mathrm{~K}-300 \mathrm{~K}$ 구간에서 저운 은도조절기 (LakeShorc $\mathrm{M} 330$ )를 이용하여 $0.1 \mathrm{~K}$ 이내로 조절하였다. 시료의 크 기는 $7 \times 1 \times 1 \mathrm{~mm}$ 이내로 하노. 전기적 설연에 유의하여 $\mathrm{GE}$ vamish로 구리시료 홀더에 부착하였다. 구리선 (Gauge \#34)을 전극단자로 사움하였고, 단자와 시료간 의 접촉은 Ag-paste를 이용하여 유지하였다. 전류는 컴 퓨터 컨트롤이 되는 정전류 공급장치(Keithley 224)를 이용하여 자체가열호과가 크게 나타나지 않도록 $1 \mathrm{~mA}$ 이내의 전규를 시로의 얌단에 공급하고옹 내보 두 선극에 서 전위차(V1)롤 정밀전압계 (Keithley 182)으로 없었다. 불균일한 전기적 접촉에 기인한 전압 호과를 상홰하기 위하여 전류의 공급 방항을 반대로 하여 전위차(V2)른 측정한 후 선기저항을 계산하였다.

$\mathrm{X}$-선 광전자 분광법(XPS)은 $\mathrm{ESCA} \mathrm{Lab} 250$ 모델 
(VG Scientifics)을 사통하였다. $1486.6 \mathrm{eV}$ 의 단색화된 $\mathrm{Al}-\mathrm{K} \alpha$ 복사선을 사용하였고, 이 때의 분해능은 대략 $\pm 0.2 \mathrm{eV}$ 였으며 $15 \mathrm{KV}, 150 \mathrm{~W}$ 에서의 광의 크기는 대랴 $500 \mu \mathrm{m}$ 이었다. 주 실의 기본 압력은 대략 $2.0 \times$ $10^{-10}$ torr로 유지되었으며 모든 결합에너지는 혹연의 C Is $(284.6 \mathrm{eV})$ 결합에너지로 보정하였다.

\section{결과 및 고참}

$\mathrm{X}$-선 회절 분석. $\mathrm{Sr}_{2} \mathrm{Ru}_{1-x} \mathrm{Cu}_{x} \mathrm{O}_{4}(0 \leq \mathrm{x} \leq 0.5)$ 화합물들이 단일상으로 합성 되었는지의 여부를 확인하기 위하여 $\mathrm{X}$-선 회절 분석을 수행하였다. $\mathrm{x}$ 값이 0.3 이하인 시료 들은 불순물 피이크가 나타나지 않은 순수한 단일상으 로 관찰 되었으나, $x$ 값어 0.4 와 0.5 인 화합물인 경우에 는 미량의 $\mathrm{Sr}_{2} \mathrm{CuO}_{3}$ 가 혼재되어 있는 것으로 확인되었 다. $\mathrm{Sr}_{2} \mathrm{Ru}_{1-x} \mathrm{Cu}_{x} \mathrm{O}_{4}(0 \leq \mathrm{x} \leq 0.3)$ 화합물들의 $\mathrm{X}$ 선 회절 분석 도는 Fig. 1에 나타내었다.

$X$-선 회절 분석 결과에 대한 Rietveld 처라로부터 얻 은 격자상수들과 결합길이를 Table 1에 수록하였고 $\mathrm{X}$-선 회절 결과로부터, 합성된 $\mathrm{Sr}_{2} \mathrm{Ru}_{\mathrm{j}-\mathrm{x}} \mathrm{Cu}_{2} \mathrm{O}_{4}$ 화합물은

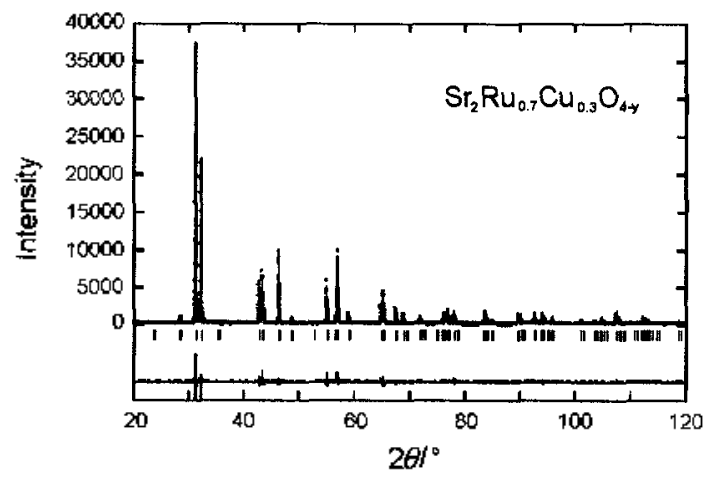

Fig. 1. The experimental (top), fitted (middle), and difference (bottom) of X-ray diffraction pattem of $\mathrm{Sr}_{2} \mathrm{Ru}_{0.7} \mathrm{Cu}_{0.7} \mathrm{O}_{4.3}$
$0 \leq x \leq 0.3$ 의 $\mathrm{Cu}$ 치환 법위에서는 모두 단일상의 정방정 계 구조를 갖는 $\mathrm{K}_{2} \mathrm{NiF}_{4}$ 형태의 구조를 취하지만, $\mathrm{Cu}$ 이 온을 Ru 이온 대신에 치환할 수 있는 농도는 $\mathrm{x}=0.3$ 이 최대라는 것을 알 수 있다. 또한, Table 1에서 알 수 있 듯이, 치환 시키는 $\mathrm{Cu}$ 의 농도를 중가할수록 격자상수 $\mathrm{a}$ 값은 조금씩 중가하지만 이와는 달리 격자상수 $\mathrm{c}$ 값 은 조금씩 감소한다.

$\mathrm{Sr}_{2} \mathrm{RuO}_{4}$ 화합물의 $\mathrm{Ru}$ 자리에 $\mathrm{Cu}$ 이혼을 치환함에 따 라 $\mathrm{RuO}_{6}$ 퐐면체 정점과 $180^{\circ}$ 떨어진 반대쪽 기저부분 의 산소 $\left(\mathrm{O}_{2}\right)$ 에서 $\mathrm{RuO}_{2}$ 사각평면의 $\mathrm{Ru}$ 금속이온 방향으 로 눌러 찌그러뜨리는 형태로 변형이 일어난다는 것을 알 수 있다. $\mathrm{Ru}$ 자리에 $\mathrm{Cu}$ 이은을 치환함에 따라 나타나 는 $\mathrm{RuO}_{6}$ 변형은 $\mathrm{Vog}$ 와 Buttrey의 연구결과와 잘 일치 한다. ${ }^{6}$ Vogt와 Buttrey는 $\mathrm{St}_{2} \mathrm{RuO}_{4}$ 에 대하영 상온에서 초 전도성이 나타나는 온도인 295-0.35 K범위에서 중성자 회절 실헙을 수행하였다. 정상상태에서 초전도 상태로 전이함에 따라 격자상수 $\mathrm{a}$ 값과 $\mathrm{c}$ 값이 점점 작아지며 이때의 $\mathrm{a}$ 값의 수축정도는 $\mathrm{c}$ 값의 수축정도 보다 횔씬 크게 나타넜다는 젓이다. 격자상수 값들의 변화로부터 계산된 c/a 비율의 온도에 따른 변화에서 알 수 있듯이, $\mathrm{Sr}_{2} \mathrm{RuO}_{4}$ 화합물은 온도가 낮아짐에 따라 전달특성이 정 상상태에서 초전도상태로 변하며 c/a 값은 조금씩 커지 는 겅항을 나타내었다. 이에 비교하여, 본 연구에서 얼 은 결과는, $\mathrm{Sr}_{2} \mathrm{RuO}_{4}$ 화합물의 $\mathrm{Ru}$ 자리에 부분적으로 치 환하는 $\mathrm{Cu}$ 이온의 농도가 중가함에 따라 c/a 값은 점점 작아지는 경향을 나타내고 있으며, $(\mathrm{Ru}, \mathrm{Cu}) \mathrm{O}_{6}$ 팔면체 의 적도방향좌 축방항 길이인 $(\mathrm{Ru}, \mathrm{Cu})-\mathrm{O}_{1}(\times 4)$ 와 $(\mathrm{Ru}, \mathrm{Cu})-$ $\mathrm{O}_{2}(\times 2)$ 의 결합길이의 변화 경향도 Vogt와 Buttery의 결 과와 잘 일치하고 있다. 즉, $\mathrm{Cu}$ 를 치환합에 따라 $(\mathrm{Ru}, \mathrm{Cu})-$ $\mathrm{O}_{1}(\times 4)$ 와 $(\mathrm{Ru}, \mathrm{Cu})-\mathrm{O}_{2}(\times 2)$ 의 결합길이의 차이가 점점 작아지는, 규칙적인 팔면체로 접근하는 국부 대칭성의 변화를 가진다는 것을 알 수 있다. 이러한 경항에서 알

Table 1. The structural parameters and bond lengths obtained from the Rietveld data

\begin{tabular}{|c|c|c|c|c|}
\hline & $\mathrm{Sr}_{2} \mathrm{RuO}_{4}$ & $\mathrm{Sr}_{2} \mathrm{Ru}_{0.9} \mathrm{Cu}_{0.1} \mathrm{O}_{4 \mathrm{y}}$ & $\mathrm{Sr}_{2} \mathrm{Ru}_{0.8} \mathrm{Cli}_{0.2} \mathrm{O}_{4-y}$ & $\mathrm{Sr}_{2} \mathrm{Ru}_{n} \mathrm{Cu}_{0,3} \mathrm{O}_{4 \mathrm{y}}$ \\
\hline $\mathrm{R}_{W P}(\%)$ & $-10 . \overline{56}$ & 10.68 & 8.54 & -8.52 \\
\hline $\mathrm{R}_{1}(\%)$ & 2.36 & 1.85 & 1.49 & 2.21 \\
\hline $\mathrm{R}_{\mathrm{P}}(\%)$ & 7.60 & 8.03 & 6.22 & 6.51 \\
\hline $\mathrm{R}_{\mathrm{E}}(\%)$ & 5.65 & 4.92 & 4.52 & 4.35 \\
\hline$a(\AA)$ & $3.8721 \mathrm{I}(4)$ & $3.88933(6)$ & $3.91129(4)$ & $3.92146(4)$ \\
\hline$c(\AA)$ & $12.7405(2)$ & $12.6726(3)$ & $12.5830(1)$ & $12.5267(1)$ \\
\hline$d a(\AA)$ & 3.2903 & 3.2583 & 3.2171 & 3.1944 \\
\hline $\mathrm{R} u-\mathrm{O}_{1}(\mathrm{x} 4)(\AA)$ & $1.9361(\mathrm{I})$ & $1.9447(1)$ & $1.9556(1)$ & $1.9607(1)$ \\
\hline $\mathrm{Ru}-\mathrm{O}_{2}(\mathrm{x} 2)(\AA)$ & $2.069(5)$ & $2.052(6)$ & $2.023(5)$ & $1.999(5)$ \\
\hline
\end{tabular}




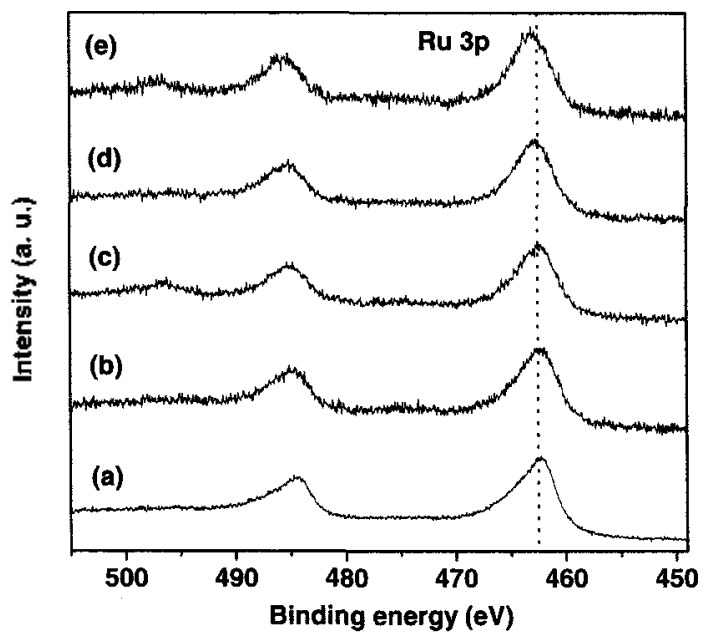

Fig. 2. XPS spectra of Ru 3p in $\mathrm{RuO}_{2}$ (a), $\mathrm{Sr}_{2} \mathrm{RuO}_{4}$ (b), $\mathrm{Sr}_{2} \mathrm{Ru}_{1,4,4} \mathrm{Cu}_{4,1} \mathrm{O}_{4-\mathrm{y}}$ (c), $\mathrm{Sr}_{2} \mathrm{Ru}_{0.8} \mathrm{Cu}_{0.2} \mathrm{O}_{4, y}$ (d), and $\mathrm{Sr}_{2} \mathrm{Ru}_{n, ?}$ $\mathrm{Cu}_{10.3} \mathrm{O}_{4-y}(\varepsilon)$.

수 있듯이 $\mathrm{Sr}_{2} \mathrm{RuO}_{4}$ 화합불에 $\mathrm{Cu}$ 룰 $\mathrm{Ru}$ 대신에 치환할 때의 전달특성은 $\mathrm{Cu}$ 농도가 증가할수록 저항이 크게 나 타날 것으로 예측되며, 이에 대한 결과 및 토론은 후술 할 것이다.

$\mathrm{X}$-선 괌-전자 분광 분석. $\mathrm{Sr}_{2} \mathrm{RuO}_{1}$ 화합물의 $\mathrm{R} u x$ 자리 에 $\mathrm{C} u$ 이온을 부북저으로 치환할 대의 전이금속이온인, $\mathrm{Ru}$ 와 $\mathrm{Cu}$ 이은의 원자가 상태를 가명하기 휘하여 $\mathrm{X}$ 선 전자 분광법을 수행하였다. Fig. 2에는 합성된 시료와 포주ㄴㅜㅜㄹ직로 채택한 $\mathrm{RuO}_{2}$ 의 Ru $3 \mathrm{p}_{3 / 2}$ 전자의 결합에너 지를 나타내었다. 모든 시료의 $\mathrm{Ru} .3 \mathrm{p}_{3 / 2}$ 전자의 결합에 너지는 대략 $462 \mathrm{cV}$ 부근에서 나타나므로. $\mathrm{Sr}_{2} \mathrm{RuO}_{4}$ 화 합물의 $\mathrm{Ru}$ 자리에 $\mathrm{Cu}$ 를 치환함에 상관없이 $\mathrm{Ru}$ 의 원자 가그 +4 를 가진다는 것을 알 수 있다. Fig. 3에는 합성 된 시료와 포죽불질로 채택한 $\mathrm{CuO}$ 의 $\mathrm{Cu} 2 \mathrm{p} m / 2$ 전자의 결합에너지를 나타내었나. 보는 시료의 $\mathrm{Cu} 2 \mathrm{p}_{3 i 2}$ 전자의 격합에너지는 대략 $932 \mathrm{eV}$ 부근에서 나타나므로 $\mathrm{Sr}_{2} \mathrm{RuO}_{4}$ 화합물의 $\mathrm{Ru}$ 자라에 치환됙 $\mathrm{Cu}$ 의 원자가는 +2 를 갖는 다는 것을 알 수 있다.

전기저함 촉정. 합섬된 다견정혐 $\mathrm{Sr}_{2} \mathrm{Ru}_{1} \mathrm{Cu}_{\mathrm{Y}} \mathrm{O}_{4}, 0.0 \leq \mathrm{x}$ $\leq 0.3)$ 화합물의 은도변화에 따른 전기저항의 변화를 Fig. 4에 도시하혔다. 모체 화합물인 $\mathrm{Sr}_{2} \mathrm{RuO}_{4}$ 화합물의 전기저항은 온도변화에 따른 전기저항의 변화가 거의 없는 금속특성을 갖는다는 것을 달 수 있으며 Ru 자라 에 $\mathrm{Cu}$ 를 치환핚에 따라 전기저항 값이 증가하는 반도 체 득성으로의 변화가 관찰돤나. $\mathrm{Sr}_{2} \mathrm{RuO}_{4}$ 화합물의 전

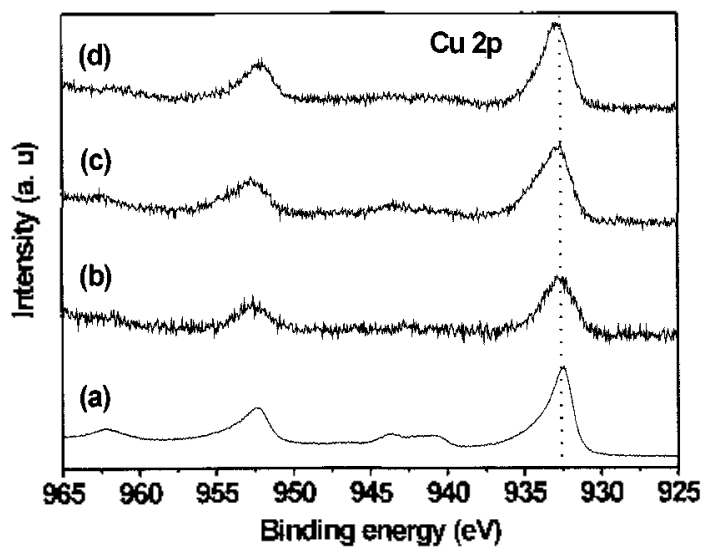

Fig. 3. XPS spectra of $\mathrm{Cu} 2 \mathrm{p}$ in $\mathrm{CuO}$ (a), $\mathrm{S}_{2} \mathrm{Ru}_{09} \mathrm{Cu}_{n_{1}} \mathrm{O}_{4-y}$

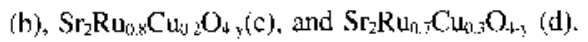

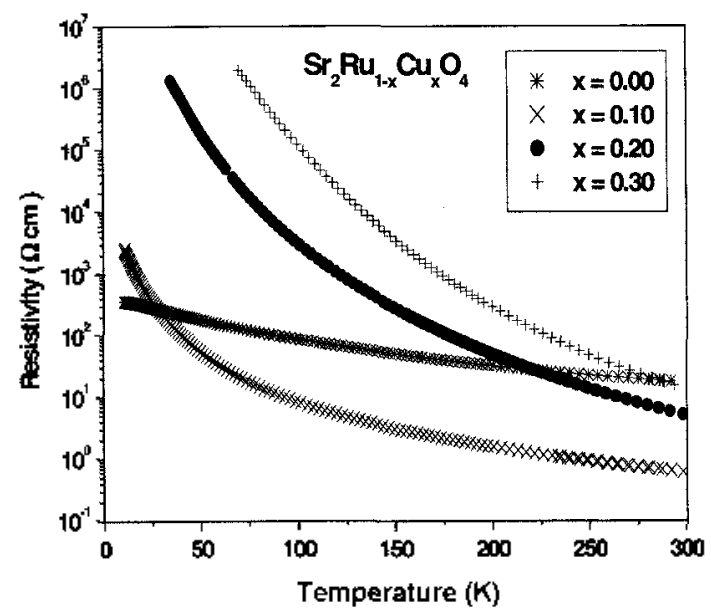

Fig. 4. The electrical resistivity of $\mathrm{Sr}_{2} \mathrm{Ru}_{1-x} \mathrm{Cu}_{x} \mathrm{O}_{4-,}$ as a function of temperature.

자구조는 $\mathrm{Ru} 4 \mathrm{~d}$ 와 $\mathrm{Cu} 2 \mathrm{p}$ 오비탈의 혼성에 의해 결정되 므로 Ru-O의 결합길이와 $\mathrm{Ru}-\mathrm{O}-\mathrm{Ru}$ 의 결합각을 포합한 $\mathrm{RuO}_{6}$ 팔면체의 국부대칭성과 매우 밀접하게 관런되어 있은을 알 수 있다. $\mathrm{Sr}_{2} \mathrm{RuO}_{4}$ 화합물의 $\mathrm{Ru}$ 자리에 부분 적으로. $\mathrm{Cu}$ 이온을 치환함에 따라 $(\mathrm{Ru}, \mathrm{Cu})-\mathrm{O}_{1}(\times 4)$ 와 $(\mathrm{Ru}, \mathrm{Cu})-\mathrm{O}_{2}(\times 2)$ 의 결합길이의 차이가 점점 작아지며 $\mathrm{RuO}_{6}$ 팔면체들의 변형정도가 줄어들면서 구칙저인 고 대칭성을 갖는 짤면체돌로 변화한다는 사실을 알 수 있 었으며, 이러한 변화양상은 Table 1에 수록된 격자상수 의 $\mathrm{c} / \mathrm{a}$ 비울의 년화로부터 결정구조의 부분적인 변화가 일어넜다는 것을 알 수 있다. 즉. $\mathrm{Sr}_{2} \mathrm{RuO}_{4}$ 화합물의 $\mathrm{Ru}$ 자리예 치환하는 $\mathrm{Cu}$ 이온의 농호롤 증가할수록 $\mathrm{Ru}-\mathrm{O}_{1}$ $(\times 4)$ 와 $\mathrm{Ru}-\mathrm{O}_{-1}(\times 2)$ 의 결합길이 차이가 $\Delta=0.1329 \AA$ 
( $\mathrm{Sr}_{2} \mathrm{RuO}_{4}$ 경우)에서 $\Delta=0.0383 \AA\left(\mathrm{Sr}_{2} \mathrm{Ru}_{0.7} \mathrm{Cu}_{0.3} \mathrm{O}_{4 y}\right.$ 경우) 으로 변하며, c/a 역시 감소하는 경향을 나타내고 있다. 이와 같은 경향은 $\mathrm{La}_{2} \mathrm{CuO}_{4}$ 구조를 갖는 초전도체의 경 향과 유사하다는 것을 알 수 있다. $\mathrm{La}_{2} \mathrm{CuO}_{4}$ 형 초전도 체는 사방정계 구조를 가지며 정방정계 구조로 상 전이 될 매에는 초전도성을 상실하계 된다. ${ }^{14,15}$ 따라서, $\mathrm{Sr}_{2} \mathrm{RuO}_{4}$ 화합물의 $\mathrm{Ru}$ 자리에 $\mathrm{Cu}$ 이온을 차한함에 따라 $(\mathrm{Ru}, \mathrm{Cu})-$ $\mathrm{O}_{1}(\times 4)$ 와 $(\mathrm{Ru}, \mathrm{Cu})-\mathrm{O}_{2}(\times 2)$ 의 결합길이의 차이가 점점 작아지며 $\mathrm{RuO}_{6}$ 팔면체들의 변형정도가 줄어둘면서 규 칙적인 고 대침성을 갖는 괄면체들로 변화함에 따라 전 자구조의 부분적인 변형에 의해 전달특성이 금속에서 반도체로 전이한다고 해석한 수 있을 것이다. 따라서, Fig. 4에 도시된 것처럼 $\mathrm{Sr}_{2} \mathrm{RuO}_{4}$ 화합물의 $\mathrm{Ru}$ 자리에 $\mathrm{Cu}$ 이혼을 치환함에 따라 전기저항이 온도변화에 따라 증가하는 반도체특성을 나타낸다고 할 수 있다.

\section{결 톤}

고상반옹으로 $\mathrm{Sr}_{2} \mathrm{Ru}_{1 . \times} \mathrm{Cu}_{x} \mathrm{O}_{4 \mathrm{y}}(0.0 \leq \mathrm{x} \leq 0.5)$ 화합물을 합 성하였다. X-선 회절 분석 결파에 대한 Rietveld 정밀 화로부터 합성된 $\mathrm{Sr}_{2} \mathrm{Ru}_{1-x} \mathrm{Cu}_{x} \mathrm{O}_{4-y}$ 화합물은 $0 \leq \mathrm{x} \leq 0.3$ 의 $\mathrm{Cu}$ 치환 범위에서는 모두 단일삼의 정방정계 구조를 갖 는 $\mathrm{K}_{2} \mathrm{NiF}_{4}$ 형태의 구조를 취하지만, $0.4 \leq \mathrm{x} \leq 0.5$ 의 법위 에서는 미량의 $\mathrm{Sr}_{2} \mathrm{CuO}_{3}$ 화합물의 회절 푀이크가 관찰 되는 이중상을 갖는 화합물로 존재한다는 사실을 알 수 있었다. $\mathrm{Sr}_{2} \mathrm{RuO}_{4}$ 화합물의 $\mathrm{Ru}$ 자리에 $\mathrm{Cu}$ 이온을 부분 적으로 치환할 때의 전이금속 이온인, Ru와 $\mathrm{Cu}$ 이온의 원자가 상태는 $\mathrm{X}$-선 전자 분광법으로 확인하였다. $\mathrm{Ru}$ $3 \mathrm{p}_{3 / 2}$ 전자와 $\mathrm{Cu} 2 \mathrm{p}_{3 / 2}$ 전자의 결합에너지 측점으로부터 $\mathrm{Ru}^{4+}, \mathrm{Cu}^{2+}$ 를 갖는 것으로 학인되었다. $\mathrm{Sr}_{2} \mathrm{Ru}_{1-x} \mathrm{Cu}_{x} \mathrm{O}_{4-y}$ $(0.0 \leq x \leq 0.3)$ 화합물의 은도변화에 따른 전기저항 값의 변 회는 이 화합물들의 결정구조의 미세변화에 따른 $\mathrm{RuO}_{6}$ 팔면체의 국부 대칭성의 변화와 연관지어 생각할 수 있 다. $\mathrm{Sr}_{2} \mathrm{RuO}_{4}$ 화합물의 $\mathrm{Ru}$ 자리에 치환하는 $\mathrm{Cu}$ 이온의 농도를 중가할수록 Ru- $\mathrm{O}_{1}(\times 4)$ 와 $\mathrm{Ru}-\mathrm{O}_{2}(\times 2)$ 의 결합길 이 차이가 $\Delta=0.1329 \AA\left(\mathrm{Sr}_{2} \mathrm{RuO}_{4}\right.$ 겸우 $)$ 에서 $\Delta=0.0383 \AA$ $\left(\mathrm{Sr}_{2} \mathrm{Ru}_{0.7} \mathrm{Cu}_{0.3} \mathrm{O}_{4-y} \text { 경우 }\right)^{\circ}$ 로 변하며, $\mathrm{c} / \mathrm{a}$ 역시 갑소하는
경항을 나타내고 있다. 이와 같은 경향은 $\mathrm{La}_{2} \mathrm{CuO}_{4}$ 형 초 전도체는 사방정계 구조를 가지며 정방정계 구조로 상 전이될 때에는 초전도성율 상실하는 경향과 유사하게 나타난다. 따라서, $\mathrm{Sr}_{2} \mathrm{RuO}_{4}$ 화합물의 $\mathrm{Ru}$ 자리에 $\mathrm{Cu}$ 이 온을 치환함에 따라 $\mathrm{RuO}_{6}$ 팔면체의 국부 대칭성의 변 화를 수반한 전작ㄱ종ㅇ 부분적인 변형이 일어나므로. 전달특성이 금속에서 반도체로 변화한다.

본 연구는 1998년도 산라대학교 교내 학술 연구비 지 훤으로 이루어졌기에 감사드럽니다.

\section{인 용 문 헌}

1. Bednorz, J. G.; Müller, K, A. Z. Phys. B, 1986, 64, 189. 2. Maeno, Y.; Hashimoto, H.; Yoshida, K.; Nishizaki, S.; Fujita. T.: Bednorz, J. G.: Lichtenberg, F. Nature, 1994, 372,532 .

3. Gardner, J. S.; Balakrishnan, G.: Paul, D. Mck. Physica C, 1995, 252, 303.

4. Gardner, J. S.; Balakrishnan, G.; Paul, D. Mck.; Haworth. C. Physica C, 1996, 265, 251.

5. Braden, M.; Moudden, A. H.; Nishizaki, S.; Maeno, Y; Fujita, T. Physica C, 1997, 273, 248.

6. Vogt, T.; Buttrey, D. J. Phys. Rev. B, 1995, 52, R9843.

7. Teske, C. L.; Müller-Buschbaum, Hk. Zn Anorg, Alg. Chem. 1969, 37l, 325.

8. WeIler, M. T.: Lines, D. R. J. Solid State Chem. 1989, 82,21 .

9. Lobo, R. C.; Berry, F. J.; Greaves, C. J. Solid State Chem. $1990,88,513$.

10. Hiroi, Z; Takano, M.; Azuma, M.: Takeda, Y. Nature, 1993, 364, 315 .

11. Shimakawa, Y.; Jorgensen. J. D.; Mitchell, J. F.; Hunter, B. A.; Shaked. H.; Hinks, D. G.; Hitterman, R. L.; Hiroi, Z; Takano, M. Physica C, 1994, 228, 73.

12. Shannon, R. D. Acta Crystallogr. 1976, 32, 751.

13. Izumi, F.; Murata. H.; Watanabe, N. J. Appl Crystallogra. 1987, 20, 411 .

14. Goodenough, J. B.: Manthitam, A.; Zhou, J. Mat. Res. Soc: Symp. Proc: 1989, 156, 339.

15. Goodenough, J. B. MRS Bulletin, 1990, May, 23. 